\title{
Refrigerant mass migration modeling and simulation for air conditioning systems
}

\author{
Bin Li ${ }^{a}$, Steffen Peuker ${ }^{b}$, Predrag S. Hrnjak ${ }^{a}$, Andrew G. Alleyne ${ }^{a, *}$ \\ a Department of Mechanical Science and Engineering, University of Illinois at Urbana-Champaign, 1206 West Green Street, MC-244, Urbana, IL 61801, USA \\ ${ }^{\mathrm{b}}$ School of Engineering, University of Alaska Anchorage, ENGR 319, 3211 Providence Drive, Anchorage, AK 99508, USA
}

\begin{abstract}
A B S T R A C T
Refrigerant mass migration and redistribution are regarded as key factors affecting the cycling performance of air conditioning and refrigeration systems. A dynamic model of an R134a automotive air conditioning system is presented as an example in this paper to capture the refrigerant migration during compressor shut-down and start-up operations. Model validation against experimental data demonstrates the capabilities of the modeling approach in predicting the refrigerant mass migration among the components during shut-down, and the resulting refrigerant redistribution behaviors during start-up. These results represent the first refrigerant mass migration prediction in a validated dynamic system model. In addition, the potential of the dynamic modeling method in performance evaluation for possible product designs and control implementation for system cycling performance improvement is discussed in this paper.
\end{abstract}

\section{Introduction}

Air conditioning and refrigeration systems are widely used in modern society to transfer energy from one physical location to another. One common way to control these systems is by on-off cycling operations. The systems operate in a cycling mode in which they stop and start the refrigerant flow to modulate the amount of cooling or heating capacity provided to the enclosed environmental spaces. Automotive air conditioning systems [1], household refrigerator-freezers [2] and refrigerated transport systems [3] are examples of such systems. The compressor in the automotive systems is continuously cycled on and off for evaporator pressure regulation to meet the cooling requirements of the passenger compartment. Similarly, the food product temperature in the refrigerated cargo space is maintained within allowable ranges through compressor shut-down and start-up cycling operations thereby ensuring the food quality and safety in transport.

The variations of refrigerant mass distribution in the on-off cycling transient conditions have been experimentally studied in different system applications, such as residential heat pump systems [4-7], household refrigerator-freezers [2,8], and automotive air conditioning systems [9]. All experimental results present the observation of refrigerant migration from the high-pressure components (i.e., condenser) to the low-pressure components (i.e., evaporator) during the compressor off period, and refrigerant

\footnotetext{
* Corresponding author. Tel.: +1 217244 9993; fax: +1 2172446534.

E-mail address: alleyne@illinois.edu (A.G. Alleyne).
}

redistribution from non-equilibrium state to steady-state refrigerant flow conditions across the mass flow components during the start-up. Cycling losses caused by the on-off operations have been identified as well and quantified experimentally and analytically $[1,2,5,6,8-15]$. Among these studies, the refrigerant migration is recognized as the major contributor to the system performance degradation. The off-cycle migration necessitates the refrigerant redistribution during the on-cycle, which reduces the system startup performance, including a reduction in evaporator capacity and an increase in the system power requirements. Several possible designs to improve system cycling performance by controlling the refrigerant migration have been discussed in the literature [1,6,8,9,14-16]. Peuker and Hrnjak [9] report a $28 \%$ reduction in compressor energy during the first $25 \mathrm{~s}$ of the start-up without cooling capacity losses when the refrigerant mass migration is prevented during the shut-down period.

Attempts have been made to model the system thermal dynamics (i.e., pressure, temperature, refrigerant mass flow rate) with compressor start-up and shut-down operations [14,17-25], but few results are available concerning the modeling of refrigerant migration behaviors. Murphy and Goldschmidt $[19,20]$ present simulated refrigerant migration results in some partial system components during start-up or shut-down transients. The refrigerant mass transients after start-up have been simulated by Koury et al. [21], and Ozyurt and Egrican [26] compare the steady-state refrigerant mass distribution of the system model with experimental measurements. Hermes and Melo [25] develop a firstprinciples household refrigerator model to simulate the system transients and point out the model potential in refrigerant 
migration analysis during the cycling operation. Additionally, Cheng et al. [27] present a validated observer design approach to estimate the immeasurable two-phase zone length in the evaporator during the start-up process, which can be used to track the refrigerant mass distribution in transients. The objective of this study is to simulate and validate the refrigerant mass distribution transients among the system components during the on-off cycling operations, and to provide industrial practitioners with dynamic modeling tools to predict system performance (i.e., refrigerant mass migration) at varying conditions. In this paper, a dynamic model of an R134a automotive air conditioning system [9] is presented as an example to capture the refrigerant migration in compressor cycling operations.

The rest of this paper is organized as follows. Section 2 describes the experimental system used for modeling and briefly introduces the experimental study on the refrigerant mass migration investigated in [9]. Using the switched modeling framework in [17], Section 3 presents a dynamic system model to simulate the refrigerant mass distribution behaviors in compressor on-off cycling transients. Specifically, the heat exchangers are developed with different model representations to accommodate the transitions of dynamic states, and keep track of the vapor and liquid refrigerant phase changes during transients. Model validation results are presented in Section 4 to demonstrate the capabilities of the developed model in capturing the refrigerant mass migration. Finally, the potential of this dynamic modeling approach in performance evaluation is discussed, and a conclusion section summarizes the main contributions of the paper.

\section{Experimental system}

The experimental system used for transient modeling and validation is an R134a automotive air conditioning system consisting of the following components: compressor, condenser, fixed orifice tube, evaporator, and accumulator. The components are installed into the experimental facility [28] with the same difference in vertical height as in the vehicle. The schematic of the experimental system is shown in Fig. 1. The system is instrumented with pressure transducers, refrigerant mass flow rate meters, and Type-T thermocouples. As seen in Fig. 1 ball valves are installed on
Table 1

Component physical parameters.

\begin{tabular}{|c|c|c|c|}
\hline Component & Parameter & Value & Units \\
\hline \multirow[t]{3}{*}{ Condenser } & Inlet header volume & 0.0001332 & $\mathrm{~m}^{3}$ \\
\hline & Internal volume & 0.0004271 & $\mathrm{~m}^{3}$ \\
\hline & Outlet header volume & 0.0001332 & $\mathrm{~m}^{3}$ \\
\hline \multirow[t]{3}{*}{ Evaporator } & Inlet header volume & 0.0001926 & $\mathrm{~m}^{3}$ \\
\hline & Internal volume & 0.0005372 & $\mathrm{~m}^{3}$ \\
\hline & Outlet header volume & 0.0001486 & $\mathrm{~m}^{3}$ \\
\hline Accumulator & Volume & 0.001331 & $\mathrm{~m}^{3}$ \\
\hline \multirow[t]{2}{*}{ Liquid tube } & Fluid flow length & 4.91 & $\mathrm{~m}$ \\
\hline & Hydraulic diameter & 0.01 & $\mathrm{~m}$ \\
\hline \multirow[t]{2}{*}{ Fixed orifice } & Internal diameter & 0.001823 & $\mathrm{~m}$ \\
\hline & Tube Length & 0.0762 & $\mathrm{~m}$ \\
\hline \multirow[t]{2}{*}{ Compressor } & Volume & 0.00022 & $\mathrm{~m}^{3}$ \\
\hline & Fixed displacement & 0.0002147 & $\mathrm{~m}^{3} / \mathrm{rev}$ \\
\hline \multirow[t]{8}{*}{ Pipes } & Compressor-to-condenser length & 2.96 & $\mathrm{~m}$ \\
\hline & Compressor-to-condenser diameter & 0.01 & $\mathrm{~m}$ \\
\hline & Fixed orifice-to-evaporator length & 0.25 & $\mathrm{~m}$ \\
\hline & Fixed orifice-to-evaporator diameter & 0.01 & $\mathrm{~m}$ \\
\hline & Evaporator-to-accumulator length & 0.72 & $\mathrm{~m}$ \\
\hline & Evaporator-to-accumulator diameter & 0.015 & $\mathrm{~m}$ \\
\hline & Accumulator-to-compressor length & 1.53 & $\mathrm{~m}$ \\
\hline & Accumulator-to-compressor diameter & 0.015 & $\mathrm{~m}$ \\
\hline
\end{tabular}

either side of each component and, by closing these ball valves simultaneously, the refrigerant mass can be trapped in each section. Table 1 contains physical parameters of the system components, and complete descriptions about the experimental system set-up and component specifications are given in [29].

Peuker and Hrnjak [9] experimentally investigate the refrigerant mass distribution among the system components during the compressor shut-down and start-up period using the quick-closing valve method and refrigerant recovery techniques. The accuracy and repeatability of the refrigerant mass measurement approach are verified. Moreover, a transparent accumulator, along with transparent inlet and outlet tubes, is used to visualize the refrigerant flow during the transient. The published experimental data are used for the validation of the dynamic model presented in this paper. The reader is encouraged to refer to $[9,29]$ for further details regarding the refrigerant mass measurement method, experimental results and analysis.

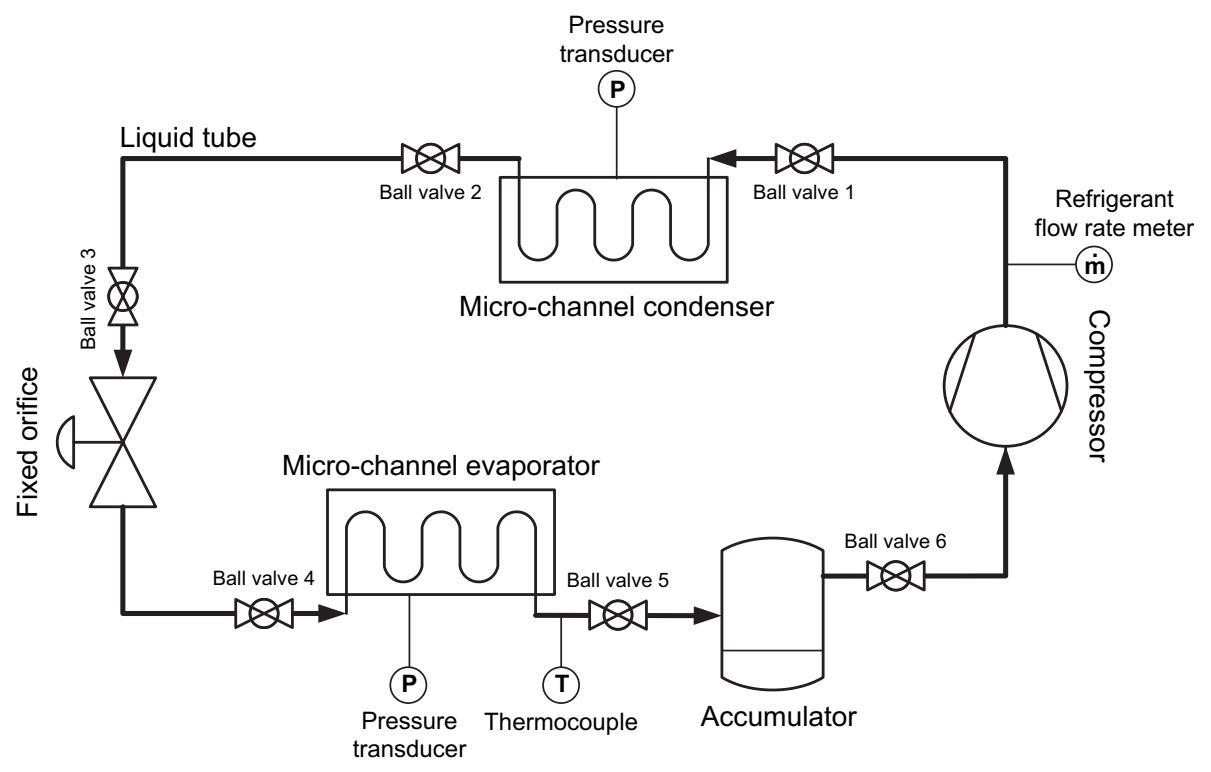

Fig. 1. Schematic of the experimental system. 


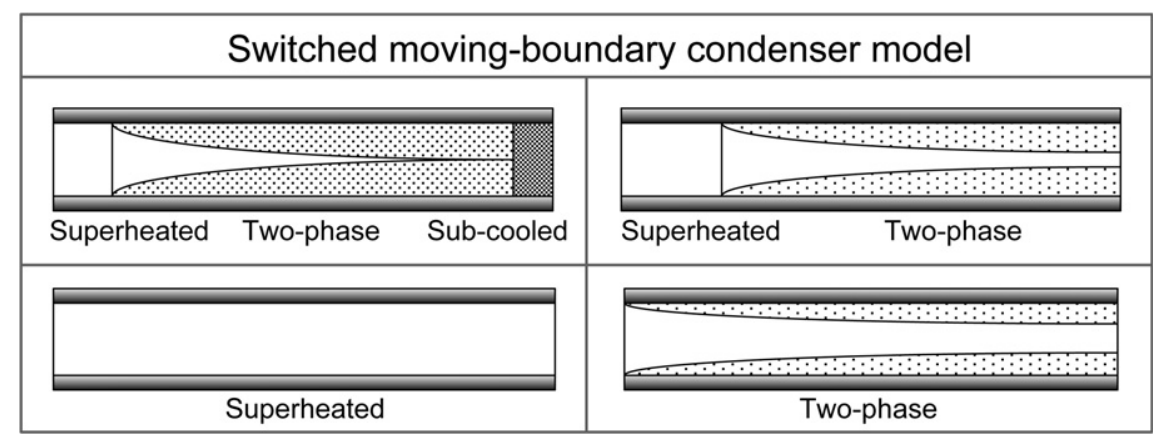

Fig. 2. Condenser model structure.

\section{System modeling}

This section is divided into three parts. Using the switched modeling framework from [17], the component models are introduced first for simulating the cycling transients of the air conditioning system. Second, methods to calculate the refrigerant mass in each component are presented, and the third part illustrates the simulation environment.

\subsection{Component modeling}

The automotive air conditioning system as shown in Fig. 1 is subdivided into five components, each of which is discussed below.

\subsubsection{Heat exchangers}

Most of the attention in the system modeling is paid to the heat exchangers, both condenser and evaporator. Since the compressor on-off cycling operations produce very large transients, a switched moving-boundary modeling framework is developed and presented in [17] to describe the refrigerant transient responses. In particular, the heat exchangers are developed to accommodate different model representations. The dynamic state vectors in Eqs. (1) and (2) represent the condenser and evaporator conditions (i.e., pressure, enthalpy, temperature, and zone locations) at each instant in time. The pseudo-state technique [30] is applied to maintain the uniform state vector, independent of model representations. Each model representation is formulated in a nonlinear descriptor form in Eq. (3) as [31], with the uniform state vector $\left(\vec{x}_{\mathrm{c}}\right.$ or $\left.\overrightarrow{x_{\mathrm{e}}}\right)$. The coefficient matrix $Z(\vec{x}, \vec{u})$ contains thermodynamic variables, and $f(\vec{x}, \vec{u})$ is a forcing function containing mass and energy balance terms. The interested reader is referred to [31] for a more complete modeling definition on the matrix $Z(\vec{x}, \vec{u})$ and the function $f(\vec{x}, \vec{u})$. An advantage of this switched approach is the tracking of the vapor and liquid refrigerant dynamic states in numerical simulation while ensuring refrigerant mass conservation during switches in system model representations.

$\overrightarrow{x_{\mathrm{c}}}=\left[\begin{array}{lllllllll}h_{\mathrm{c} 1} & P_{\mathrm{c}} & h_{\mathrm{c} 3} & \zeta_{\mathrm{c} 1} & \zeta_{\mathrm{c} 2} & T_{\mathrm{c} 1, \mathrm{w}} & T_{\mathrm{c} 2, \mathrm{w}} & T_{\mathrm{c} 3, \mathrm{w}} & \bar{\gamma}_{\mathrm{c}}\end{array}\right]^{\mathrm{T}}$ $\vec{x}_{\mathrm{e}}=\left[\begin{array}{llllll}\zeta_{\mathrm{e} 1} & P_{\mathrm{e}} & h_{\mathrm{e} 2} & T_{\mathrm{e} 1, \mathrm{w}} & T_{\mathrm{e} 2, \mathrm{w}} & \bar{\gamma}_{\mathrm{e}}\end{array}\right]^{\mathrm{T}}$

$Z(\vec{x}, \vec{u}) \cdot \dot{\vec{x}}=f(\vec{x}, \vec{u})$

In this study, besides the modeling assumptions given in [17], additional assumptions are made as follows:

- The micro-channel heat exchangers (see Fig. 1) can be modeled using a moving-boundary approach [32].

- The micro-channel heat exchanger is assumed to be a long horizontal single-pass tube with a reduced mass flow rate by a factor of $1 / n$, where $n$ is the number of parallel-passes. Furthermore, relevant physical parameters, such as heat exchanger mass and air-flow cross-sectional area, are reduced by the same factor [32].

- Refrigerant maldistribution due to the parallel-passes is not considered in the heat exchanger model.

- The headers of both heat exchangers are not taken into account.

- The two-phase slip flow can be modeled adequately through a void fraction correlation.

- The air passing over the heat exchangers is assumed to be in dry conditions.

Based on the switched modeling method and experimental study [9], the condenser is developed to consist of four different model representations in Fig. 2, and two different model representations, as shown in Fig. 3, are used for the evaporator. The dynamic states in Eqs. (1) and (2) are applied to describe the heat exchanger transients, where the mean void fraction $\bar{\gamma}_{\mathrm{c}}$ and $\bar{\gamma}_{\mathrm{e}}$ are used for switching purposes [30]. The NTU method [30] is applied to represent the relationship between air inlet and outlet temperature in the heat exchangers, as shown in Eqs. (4) and (5). The refrigerant-side governing equations are derived by considering mass and energy conservation in each zone (i.e., superheated zone, two-phase zone). Take the one-zone (two-phase) evaporator model in Fig. 3 for example, Eqs. (6) and (7) describe the two-phase refrigerant dynamics, and the pseudo-state equation (8) is used to

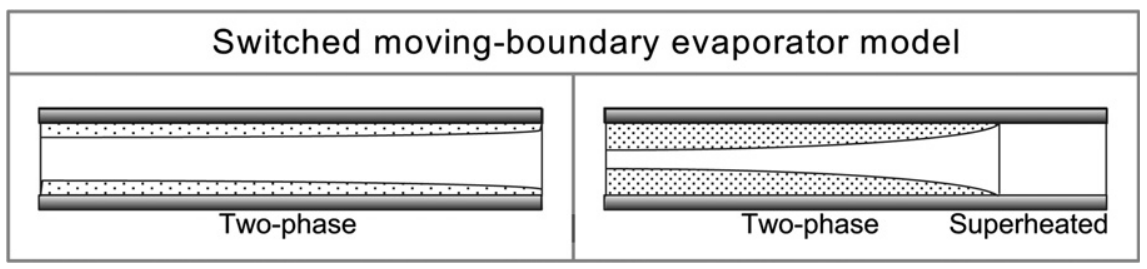

Fig. 3. Evaporator model structure. 


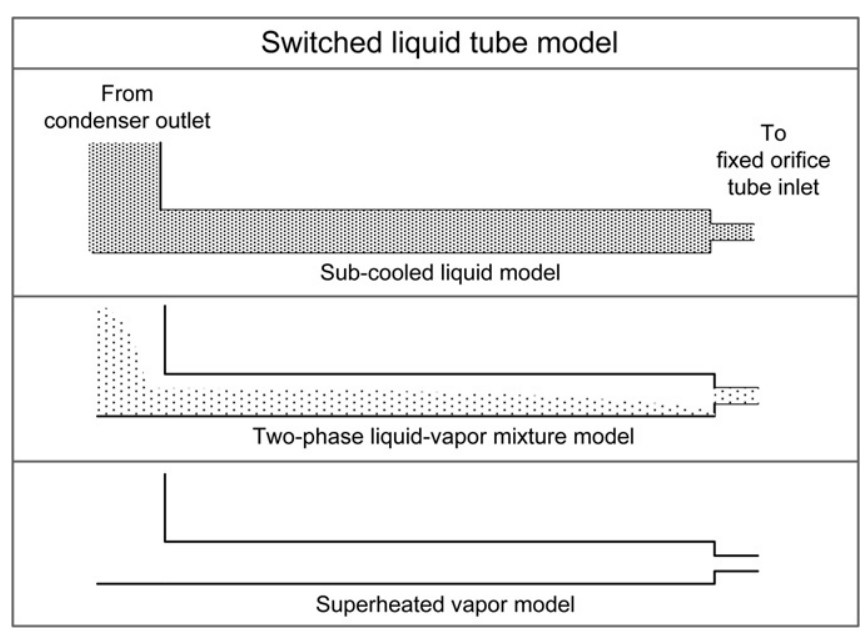

Fig. 4. Liquid tube model structure.

model the refrigerant enthalpy state in the inactive superheated zone by tracking the saturated vapor enthalpy.

$T_{\mathrm{o}, \mathrm{air}, j}=T_{\mathrm{w}, j}+\left(T_{\mathrm{i}, \mathrm{air}}-T_{\mathrm{w}, j} \exp (-\mathrm{NTU})\right)$

$\mathrm{NTU}=\frac{\alpha_{\mathrm{air}} A_{\mathrm{air}}\left(1-\left(A_{\mathrm{fin}} / A_{\mathrm{air}}\right)\left(1-\eta_{\mathrm{fin}, \mathrm{air}}\right)\right)}{\dot{m}_{\mathrm{air}} C_{\mathrm{air}}}$

$\frac{\zeta_{\mathrm{e} 1}}{\rho_{\mathrm{e} 1}} \frac{\delta \rho_{\mathrm{e} 1}}{\delta P_{\mathrm{e}}} \frac{\mathrm{d} P_{\mathrm{e}}}{\mathrm{d} t}+\frac{\zeta_{\mathrm{e} 1}}{\rho_{\mathrm{e} 1}} \frac{\delta \rho_{\mathrm{e} 1}}{\delta \bar{\gamma}_{\mathrm{e}}} \frac{\mathrm{d} \bar{\gamma}_{\mathrm{e}}}{\mathrm{d} t}=\frac{\dot{m}_{\mathrm{i}, \mathrm{e}}-\dot{m}_{\mathrm{o}, \mathrm{e}}}{\rho_{\mathrm{e} 1} V_{\mathrm{e}}}$

$\left[\frac{\delta h_{\mathrm{e} 1}}{\delta P_{\mathrm{e}}}-\frac{1}{\rho_{\mathrm{e} 1}}\right] \frac{\mathrm{d} P_{\mathrm{e}}}{\mathrm{d} t}+\frac{\delta h_{\mathrm{e} 1}}{\delta \bar{\gamma}_{\mathrm{e}}} \frac{\mathrm{d} \bar{\gamma}_{\mathrm{e}}}{\mathrm{d} t}$

$=\frac{\dot{Q}_{\mathrm{e} 1}+\dot{m}_{\mathrm{i}, \mathrm{e}}\left(h_{\mathrm{i}, \mathrm{e}}-h_{\mathrm{e} 1}\right)-\dot{m}_{\mathrm{o}, \mathrm{e}}\left(h_{\mathrm{o}, \mathrm{e}}-h_{\mathrm{e} 1}\right)}{\rho_{\mathrm{e} 1} V_{\mathrm{e}} \zeta_{\mathrm{e} 1}}$

$\frac{\mathrm{d} h_{\mathrm{e} 2}}{\mathrm{~d} t}=K\left(h_{\mathrm{g}}-h_{\mathrm{e} 2}\right)$

The conditions to trigger the switch from the one-zone to the two-zone (two-phase and superheated) evaporator model are given in Eqs. (9) and (10), and are stated as, "the existence and further increase of excess vapor in the two-phase zone indicate the occurrence of the superheated zone in the evaporator.'

$\zeta_{\mathrm{e} 1}\left(\bar{\gamma}_{\mathrm{e}}-\bar{\gamma}_{\mathrm{etot}}\right)>\zeta_{\mathrm{emin}}$

and

$\frac{\mathrm{d} \bar{\gamma}_{\mathrm{e}}}{\mathrm{d} t}>0$

where the term on the left side of Eq. (9) represents the normalized

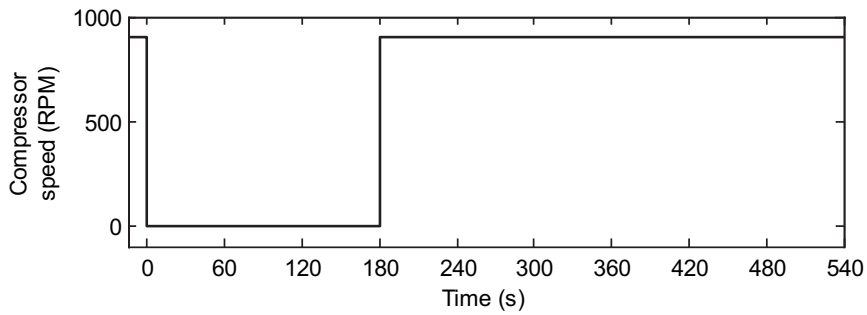

Fig. 5. Compressor speed input for validation.
Table 2

System inputs for model validation.

\begin{tabular}{llll}
\hline Input & $\begin{array}{l}\text { Step time } \\
\text { for shut-down }\end{array}$ & $\begin{array}{l}\text { Before } \\
\text { shut-down }\end{array}$ & $\begin{array}{l}\text { Step time } \\
\text { for start-up }\end{array}$ \\
\hline Compressor speed & $0 \mathrm{~s}$ & $900 \mathrm{rpm}$ & $180 \mathrm{~s}$ \\
Cond. air mass flow rate & & $0.525 \mathrm{~kg} / \mathrm{s}$ & \\
Evap. air mass flow rate & & $\begin{array}{c}0.156 \mathrm{~kg} / \mathrm{s} \\
35^{\circ} \mathrm{C}\end{array}$ & \\
Cond. air inlet temperature & $35^{\circ} \mathrm{C}$ & \\
Evap. air inlet temperature & & & \\
\hline
\end{tabular}

length of excess superheated vapor based on the mean void fraction value, and $\zeta_{\text {emin }}$ on the right side is regarded as a tunable switching threshold indicating the minimum dimensionless length of the superheated zone within the total evaporator tube length. The reader is referred to [17] for detailed descriptions about the derivations of governing equations in the different model representations, as well as switching schemes to simulate the cycling dynamics.

\subsubsection{Accumulator}

The accumulator is a key component in the automotive air conditioning system. Its primary function is to store excess refrigerant mass to ensure system capacity over a large range of operating conditions. Meanwhile, it captures two-phase refrigerant thus preventing damage to the compressor. Two dynamic states, refrigerant pressure $P_{\mathrm{ac}}$, and refrigerant enthalpy $h_{\mathrm{ac}}$, are defined to describe the refrigerant dynamics inside the accumulator. By applying mass and energy conservation principles, the governing equations are given below.

$$
\begin{aligned}
& \frac{\delta \rho_{\mathrm{ac}}}{\delta P_{\mathrm{ac}}} \frac{\mathrm{d} P_{\mathrm{ac}}}{\mathrm{d} t}+\frac{\delta \rho_{\mathrm{ac}}}{\delta h_{\mathrm{ac}}} \frac{\mathrm{d} h_{\mathrm{ac}}}{\mathrm{d} t}=\frac{\dot{m}_{\mathrm{i}, \mathrm{ac}}-\dot{m}_{\mathrm{o}, \mathrm{ac}}}{V_{\mathrm{ac}}} \\
& -\frac{1}{\rho_{\mathrm{ac}}} \frac{\mathrm{d} P_{\mathrm{ac}}}{\mathrm{d} t}+\frac{\mathrm{d} h_{\mathrm{ac}}}{\mathrm{d} t} \\
& =\frac{(\mathrm{UA})_{\mathrm{ac}}\left(T_{\mathrm{amb}}-T_{\mathrm{ac}}\right)+\dot{m}_{\mathrm{i}, \mathrm{ac}}\left(h_{\mathrm{i}, \mathrm{ac}}-h_{\mathrm{ac}}\right)+\dot{m}_{\mathrm{o}, \mathrm{ac}}\left(h_{\mathrm{i}, \mathrm{ac}}-h_{\mathrm{ac}}\right)}{\rho_{\mathrm{ac}} V_{\mathrm{ac}}}
\end{aligned}
$$

Table 3

Model validation operating conditions.

\begin{tabular}{lll}
\hline Evaporator & Units & Value \\
Pressure & $\mathrm{kPa}$ & 340.15 \\
Inlet enthalpy & $\mathrm{kJ} / \mathrm{kg}$ & 118.92 \\
Refrigerant mass & $\mathrm{kg}$ & 0.16852 \\
Accumulator & $\mathrm{Units}$ & \\
Pressure & $\mathrm{kPa}$ & Value \\
Refrigerant mass & $\mathrm{kg}$ & 334.24 \\
Compressor & $\mathrm{Units}$ & 0.18272 \\
Inlet pressure & $\mathrm{kPa}$ & Value \\
Outlet pressure & $\mathrm{kPa}$ & 328.33 \\
Inlet temperature & ${ }^{\circ} \mathrm{C}$ & 1345.12 \\
Outlet temperature & ${ }^{\circ} \mathrm{C}$ & 4.92 \\
Refrigerant mass flow rate & $\mathrm{kg} / \mathrm{s}$ & 62.34 \\
Refrigerant mass & $\mathrm{kg}$ & 0.034 \\
Condenser & $\mathrm{Units}$ & 0.05974 \\
Pressure & $\mathrm{kPa}$ & Value \\
Refrigerant inlet temperature & ${ }^{\circ} \mathrm{C}$ & 1341.38 \\
Refrigerant mass & $\mathrm{kg}$ & 63 \\
Liquid tube & $\mathrm{Units}$ & 0.2196 \\
Refrigerant mass & $\mathrm{kg}$ & Value \\
Fixed orifice tube & $\mathrm{Units}$ & 0.36396 \\
Inlet pressure & $\mathrm{kPa}$ & Value \\
Outlet pressure & $\mathrm{kPa}$ & 1312 \\
Inlet temperature & ${ }^{\circ} \mathrm{C}$ & 340.15 \\
Refrigerant mass flow rate & $\mathrm{kg} / \mathrm{s}$ & 47.07 \\
\hline & & 0.034 \\
\hline
\end{tabular}




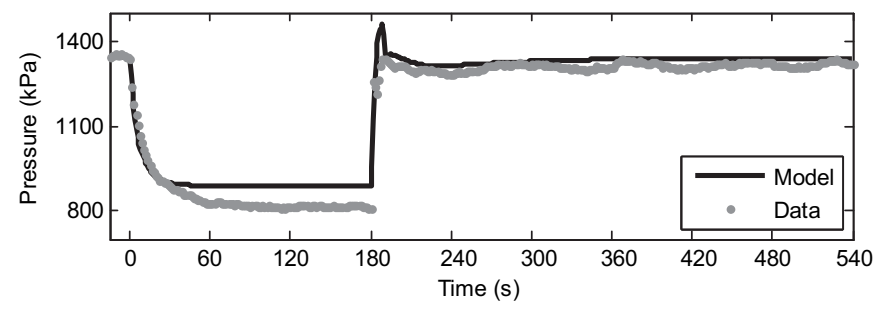

Fig. 6. Condenser pressure.

where the term $(\mathrm{UA})_{\mathrm{ac}}\left(T_{\mathrm{amb}}-T_{\mathrm{ac}}\right)$ represents the heat transfer rate from the ambient air to the refrigerant inside the accumulator. The heat transfer is considered since it influences the refrigerant mass migration of the accumulator.

\subsubsection{Liquid tube}

The liquid tube is treated as a separate component, since it involves dramatic refrigerant flow dynamics in system shut-down and start-up transients as discussed in $[19,20]$. The authors in $[19,20]$ choose two different approaches to model the liquid tube: a discretized volume approach in shut-down and a tank model method at start-up transients. In this study, a simplified switched liquid tube model with three different representations, shown in Fig. 4, is developed to represent the refrigerant migration, and the refrigerant pressure drop along the liquid tube is neglected. The structure of refrigerant-side mass and energy governing equations in each model representation is similar to Eqs. (11) and (12), and the mean void fraction $\bar{\gamma}_{l t}$ in the liquid tube, which is a function of refrigerant pressure $P_{\mathrm{lt}}$ and enthalpy $h_{\mathrm{lt}}$, determines the model switching criteria [17]. For example, the switch occurs from the two-phase mixture to the superheated vapor model (see Fig. 4) when the switching conditions, as given in Eqs. (13) and (14), are satisfied.

$\bar{\gamma}_{\mathrm{lt}}>1$

and

$\frac{\mathrm{d} \bar{\gamma}_{\mathrm{lt}}}{\mathrm{d} t}>0$

\subsubsection{Fixed orifice tube and compressor}

Since the dynamics of the mass flow devices (fixed orifice tube and compressor) are generally an order of magnitude faster than those of the heat exchangers [31], these two components are considered to be static models. As presented in $[19,20]$, the mass flow rate across the fixed orifice tube influences the refrigerant pressure in both heat exchangers as well as the refrigerant mass distribution during the cycling transients. Therefore, an accurate valve model is necessary. Eq. (15) is used to calculate the orifice mass flow rate, where the flow coefficient $C_{\mathrm{f}}$ is determined via

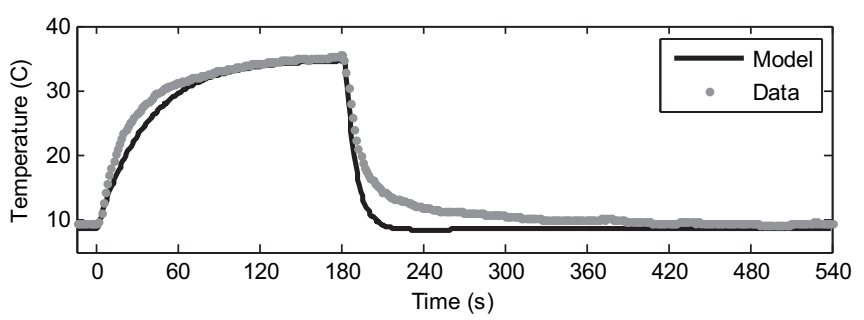

Fig. 8. Evaporator air outlet temperature.

a semi-empirical mapping approach [33], and the refrigerant density $\rho_{\mathrm{V}}$ is assumed to be a function of the refrigerant inlet conditions (i.e., liquid-vapor mixture, or vapor) to the orifice tube, as given in (16).

$\dot{m}_{\mathrm{v}}=C_{\mathrm{f}} \sqrt{\rho_{\mathrm{v}}\left(P_{\mathrm{lt}}-P_{\mathrm{e}}\right)}$

$\rho_{\mathrm{v}}=\rho\left(P_{\mathrm{lt}}, h_{i, \mathrm{v}}\right)$

The compressor model illustrated in [17] has been demonstrated to predict the refrigerant mass flow after system start-up with sufficient accuracy to be useful for simulation purposes. The compressor mass flow rate is computed by:

$\dot{m}_{k}=V_{k} \omega_{k} \rho_{k} \eta_{\mathrm{vol}}$

where $V_{k}$ is the cylinder volume, $\omega_{k}$ is the compressor speed, and $\rho_{k}$ is the refrigerant inlet density. The volumetric efficiency $\eta_{\mathrm{vol}}$ is found using a performance mapping approach similar to the one given in [33].

\subsection{Refrigerant mass calculation}

Approaches are explored here to evaluate the refrigerant mass distribution behaviors in the on-off cycling operation. Poggi et al. [34] presents a summary of available refrigerant mass calculation methods in the literature. The authors in [34] also point out that the major challenge is the mass evaluation in two-phase components, such as heat exchangers. For general numerical simulation, the refrigerant mass migration in each system component can be obtained by Eq. (18) with known refrigerant inlet and outlet mass flow rate conditions. An alternative way to evaluate the refrigerant mass distribution in heat exchangers during transients is using the mean void fraction $\bar{\gamma}_{c}$ and $\bar{\gamma}_{e}$, which is an integral form of a local void fraction $[30,35]$. The Zivi void fraction correlation [36] is applied in this study, since it shows a good agreement with measurements as reported in [37,38]. The two-phase and single-phase (vapor or liquid) refrigerant mass calculations in the heat exchangers are given in Eqs. (19) and (20).

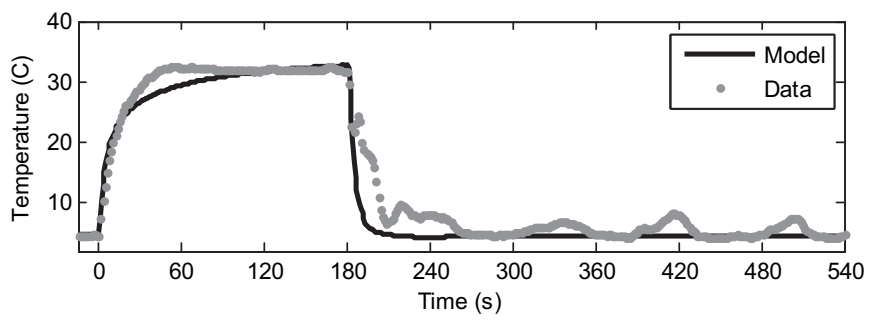

Fig. 9. Evaporator refrigerant outlet temperature.

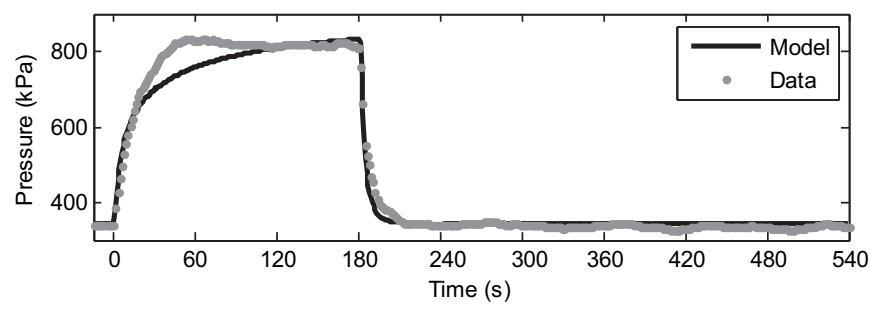

Fig. 7. Evaporator pressure. 


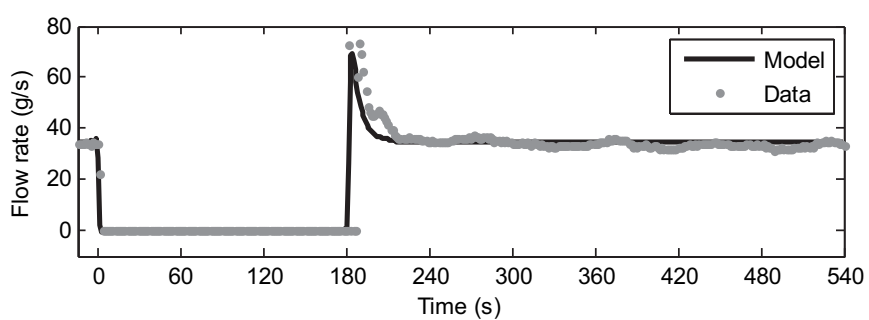

Fig. 10. Refrigerant mass flow rate across the compressor.

$M_{\text {component }}=M_{\text {steady-state }}+\int\left(\dot{m}_{\mathrm{i}}-\dot{m}_{\mathrm{o}}\right) \mathrm{d} t$

$M_{\text {two-phase, exchangers }}=\left(\bar{\gamma} \rho_{\mathrm{g}}+(1-\bar{\gamma}) \rho_{\mathrm{f}}\right) \zeta_{\text {two-phase }} V_{\text {exchangers }}$

$M_{\text {single-phase,exchangers }}=\rho_{\text {single-phase }} \zeta_{\text {single-phase }} V_{\text {exchangers }}$

The total refrigerant mass in the automotive air conditioning system (see Fig. 1) is described below.

$$
\begin{aligned}
M_{\text {total }}= & M_{\text {exchangers }}+M_{\text {accumulator }}+M_{\text {liquid_tube }}+M_{\text {compressor }} \\
& +M_{\text {pipes }}
\end{aligned}
$$

where the calculation of the single-phase refrigerant mass in components, such as superheated vapor in pipes, is based on the refrigerant density and component volume information.

\subsection{Simulation environment}

To validate the refrigerant mass migration performance, the component models described above, along with pipe models connecting each component, are implemented in Thermosys [31], a Matlab/Simulink toolbox for simulation. The pipe models calculate pressure drops between any two components. The inputs to each model are generally the outputs of other component models. For instance, the refrigerant inlet and outlet mass flow rates are the evaporator model inputs, yet they themselves are the outputs of the fixed orifice tube and compressor model, respectively. The air-side heat transfer coefficients in the heat exchangers are calculated by $j$-factor correlations [39]. The two-phase refrigerant-side heat transfer coefficients are defined by empirical equations. Specifically, the two-phase refrigerant heat transfer correlation developed by Dobson and Chato [40] is chosen for the condenser, and the evaporator model uses the correlation from Wattelet et al. [41]. A Colburn modulus-Reynolds number correlation [42] is applied for the single-phase refrigerant-side heat transfer coefficient

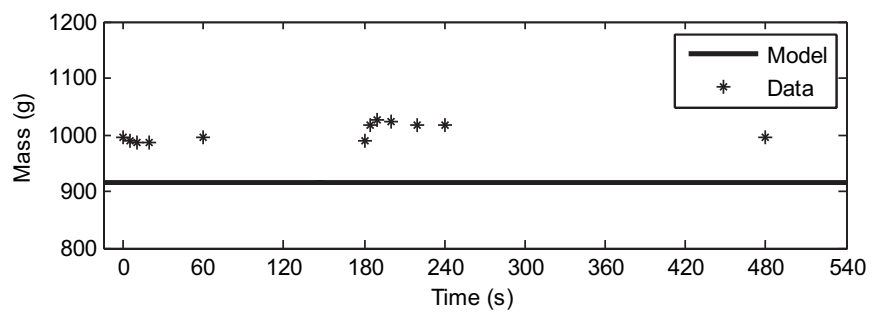

Fig. 11. Total refrigerant mass in the system.

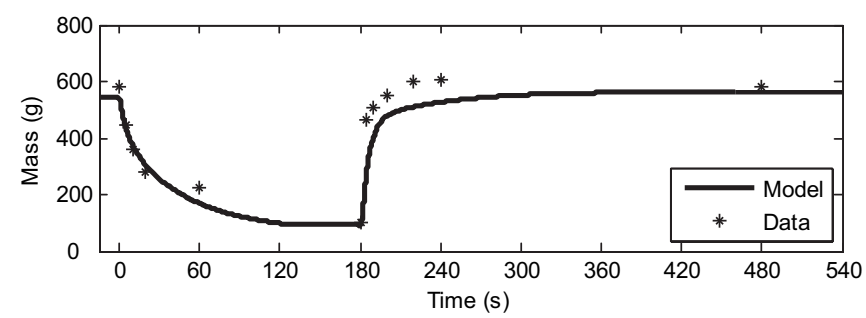

Fig. 12. Refrigerant mass migration in the high-pressure components.

calculation. More information about the heat transfer calculations in transients and numerical solution procedures can be found in [17].

\section{Model validation}

As mentioned in Section 2, the refrigerant mass migration experimental data presented in [9] are used for transient validation in this study. The model validation scenario, which is identical to the experimental scenario in [9], includes shut-down and start-up step changes in compressor speed (see Fig. 5) while maintaining the dry air-flow rates across the heat exchangers. The interested reader is referred to [29] for experimental study regarding the effect of water vapor on the refrigerant migration during the cycling operations. The steps in system inputs for the model validation here are summarized in Table 2 along with the condenser and evaporator air inlet temperature conditions. The compressor shut-down time period is $3 \mathrm{~min}$. The operating conditions before system input changes, including the refrigerant mass distribution among the components, are listed in Table 3.

By closing the ball valves shown in Fig. 1 simultaneously, the refrigerant masses are kept in five sections: compressor, condenser, liquid tube, evaporator and accumulator. The refrigerant mass distribution in each section is measured at the following times during the transient scenario: 0 (compressor turns off), 5, 10, 20, 60, 180 (compressor turns on), 185, 190, 200, 220, 240 and 480. All times are in seconds. A total refrigerant mass of $1000 \mathrm{~g}$ is used for the experimental study, and the pressure and temperature measurements are taken every $1.5 \mathrm{~s}$.

The plots in Figs. 6-10 compare the experimental results with various system model outputs. During the off cycle, the refrigerant migrates from the high-pressure to the low-pressure components through the fixed orifice tube, which results in the heat exchanger pressure changes as seen in Figs. 6 and 7. The evaporator air outlet temperature, as shown in Fig. 8, increases towards the ambient temperature $\left(35^{\circ} \mathrm{C}\right)$ as the thermal mass of the heat exchanger and refrigerant mass inside approach an equilibrium condition. In addition, the system model predicts the transients of the refrigerant mass flow rate across the compressor at start-up shown in Fig. 10.

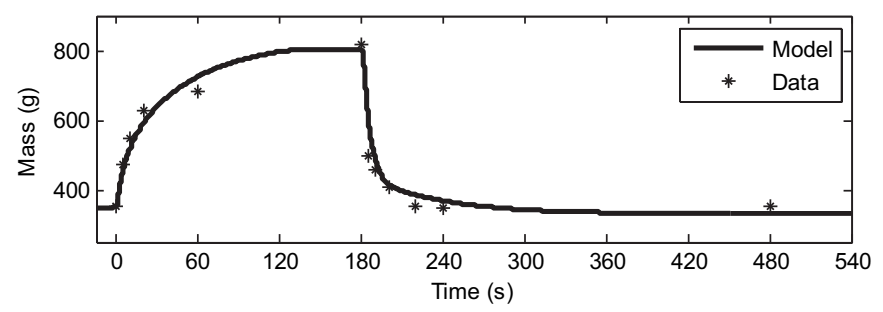

Fig. 13. Refrigerant mass migration in the low-pressure components. 


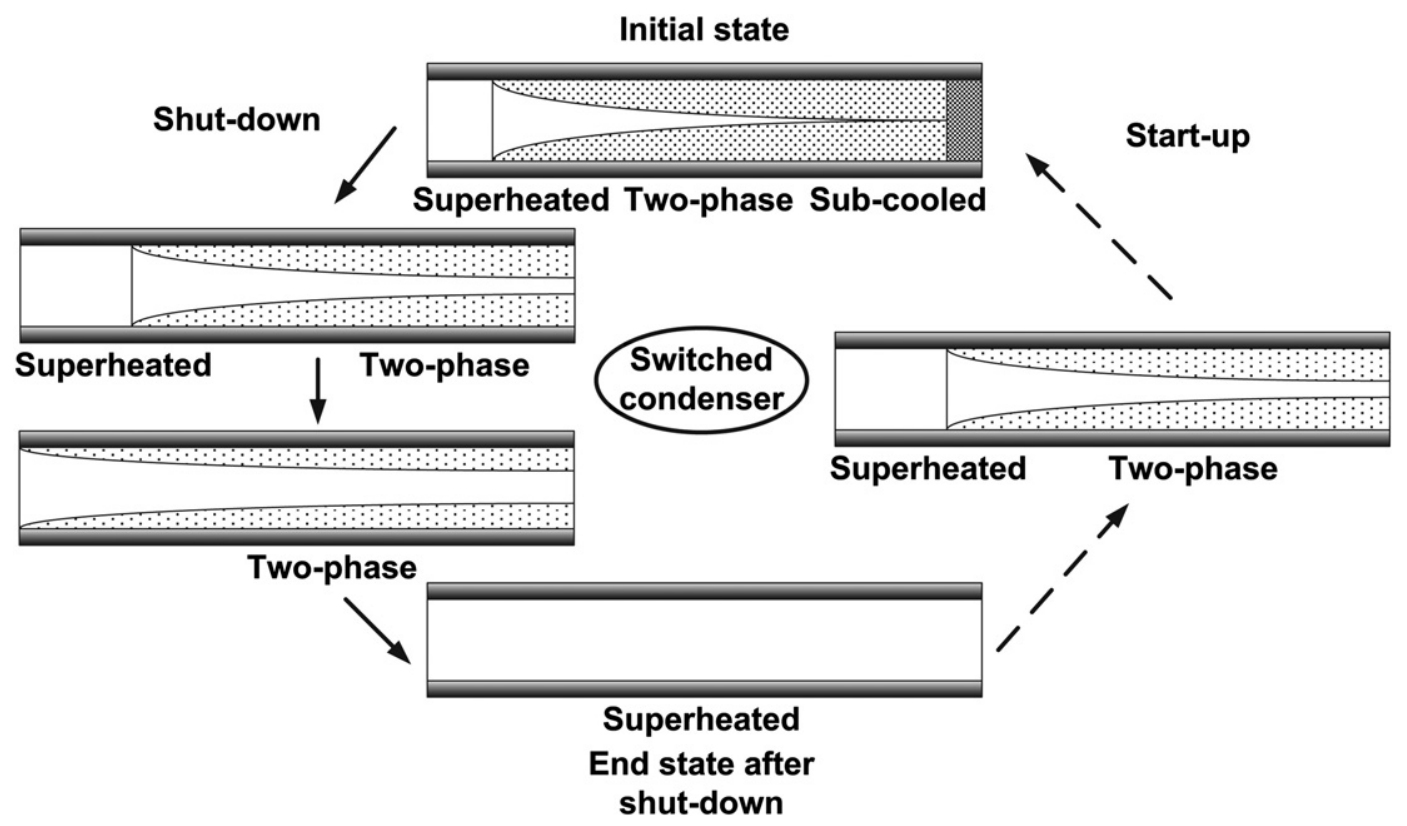

Fig. 14. Switching schemes in the condenser.

The total refrigerant mass comparison between experimental measurement and system model prediction is given shown in Fig. 11. The total refrigerant mass in the experimental system differs up to $2.7 \%$ from the target refrigerant mass of $1000 \mathrm{~g}$ as a result of the measurement technique used. The amount of refrigerant mass is maintained in the transient simulation, which further proves the validity of the switched modeling approach discussed in Section 3. There are three main reasons accounting for the approximately $10 \%$ mass prediction deviation:

- The volume of heat exchanger headers is neglected in the modeling process.

- The refrigerant mass in the compressor $M_{\text {compressor }}$ (see Eq. (21)) is neglected in the total refrigerant mass calculation, since there is little change to the refrigerant amount in the compressor [7,9].

- The impact of choices of void fraction correlations on the refrigerant mass evaluation is discussed in $[34,38]$, and the Zivi correlation [36] used here underestimates the refrigerant mass against the experimental results with a maximal deviation of $10 \%$.

The refrigerant migration during the transient scenario is described in Figs. 12 and 13. The experimental results show that before the system turns off, $58 \%$ of the total refrigerant mass is located in the high-pressure components (condenser and liquid

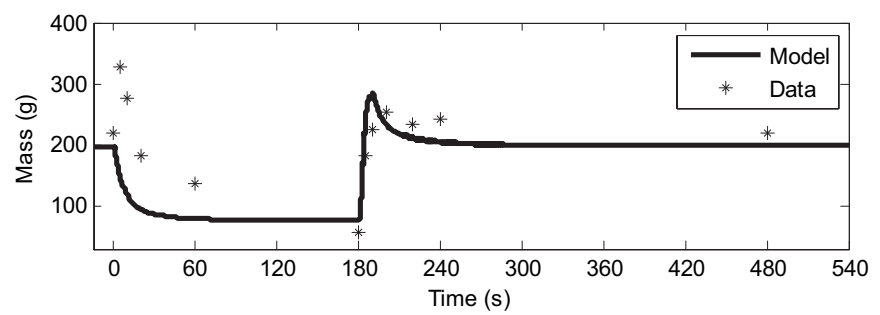

Fig. 15. Refrigerant mass migration in the condenser. tube). Three minutes after the compressor is stopped, only $11 \%$ of the total refrigerant mass is found in these components (see Fig. 12). It can also be seen that the majority of the mass migration takes place in the first minute after system shut-down, and the refrigerant redistribution during start-up is almost completely achieved after $1 \mathrm{~min}$ [9]. To quantify the model performance, a mass prediction error method, as computed in Eq. (22) with the root mean square (RMS) value, is applied here. $N=12$ is the number of data samples available. Approximately $8 \%$ error is found in predicting the refrigerant mass migration in the high-pressure components, and the prediction error is $4 \%$ for the migration in the low-pressure components as shown in Fig. 13.

$E_{\text {error }}=\frac{1}{M_{\text {total }}} \sqrt{\frac{\sum_{k=1}^{12}\left(M_{\text {model }, k}-M_{\text {experiement }, k}\right)^{2}}{12}}$

Fig. 14 describes the dynamic switching of different model representations in the condenser model structure (see Fig. 2) for this validation scenario, where relevant switching criteria are discussed in [17]. The condenser model switches from the initial three-zone (superheated, two-phase and sub-cooled) model to the final one-zone (superheated) model during the off cycle. The vapor and liquid refrigerant transients are tracked through the model switching techniques, which enables the calculation of refrigerant mass variations using Eqs. (19) and (20). The refrigerant mass migration in the condenser component is given in Fig. 15, while Fig. 16 presents the refrigerant migration inside the liquid tube component. Two minutes after system shut-down, the liquid tube is filled with superheated vapor, which agrees with the experimental observation [9]. The initial high compressor mass flow rate (see Fig. 10) and low orifice tube mass flow rate explain the overshoot of the refrigerant mass migration in the condenser in the first $20 \mathrm{~s}$ of the start-up.

As shown in Fig. 13, prior to system start-up, over $80 \%$ of the total refrigerant mass is located in the low-pressure components (evaporator and accumulator). The experimental study [9] shows that the evaporator is starved $5 \mathrm{~s}$ after the start-up operation, which coincides with the occurrence of superheated vapor at the 


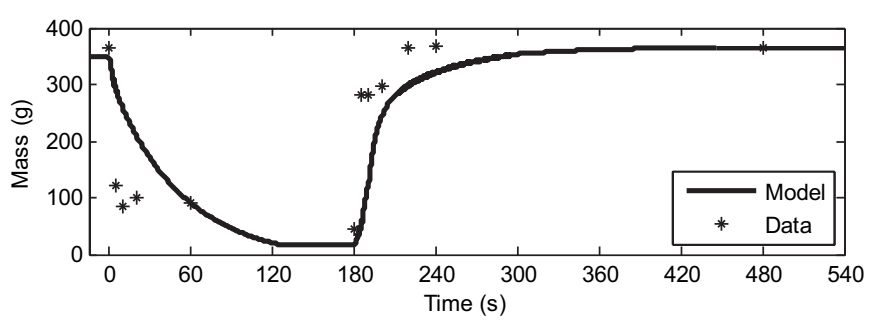

Fig. 16. Refrigerant mass migration in the liquid tube.
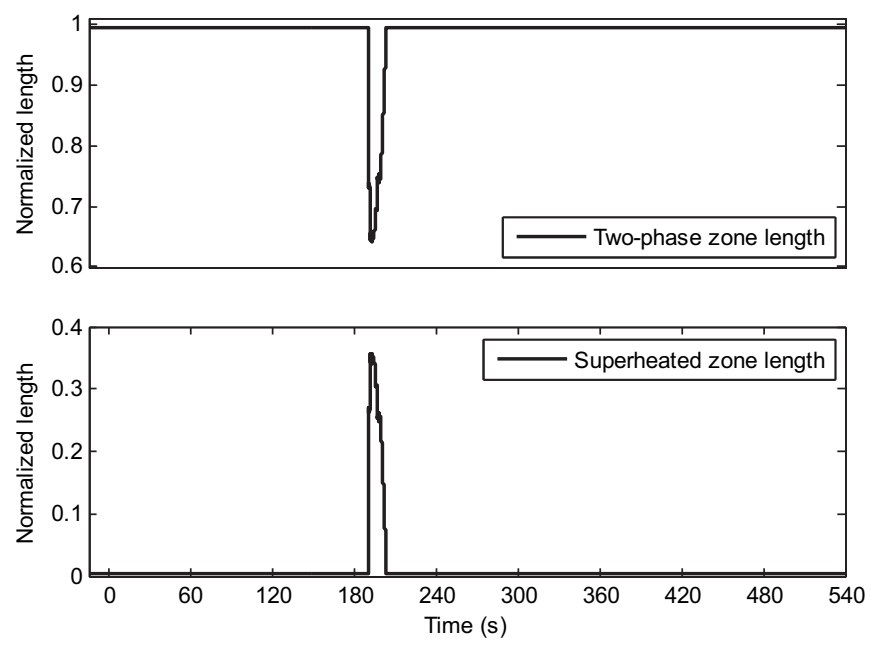

Fig. 17. Evaporator two-phase and superheated zone length trace in transients.

evaporator outlet, since the relatively warm thermal mass of the evaporator leads to the evaporation of the refrigerant inside, and the refrigerant mass is migrated towards the condenser before returning to the steady-state distribution as described in Fig. 15. Similar phenomena are observed in [8,11], and Fig. 17 highlights the dynamic switching in terms of the length traces of two different zones in the evaporator model. The evaporator model stays in the one-zone (two-phase) model representation (see Fig. 3) during the shut-down transients, where the normalized length of the superheated vapor zone is set to be $0.5 \%$ of the total evaporator tube length, and the pseudo-states [17] are applied to represent the dynamics of this inactive superheated zone. A switch occurs from the one-zone to the two-zone (two-phase and superheated) model after start-up, since the switching conditions described in Eqs. (9) and (10) are satisfied and the superheated zone becomes active. The normalized superheated zone length is tracked until it becomes less than the switching threshold (0.5\%), and then the two-zone evaporator model representation switches back to the one-zone model for steady-state conditions, as presented in Fig. 17. The zone lengths are dimensionless and normalized based on the

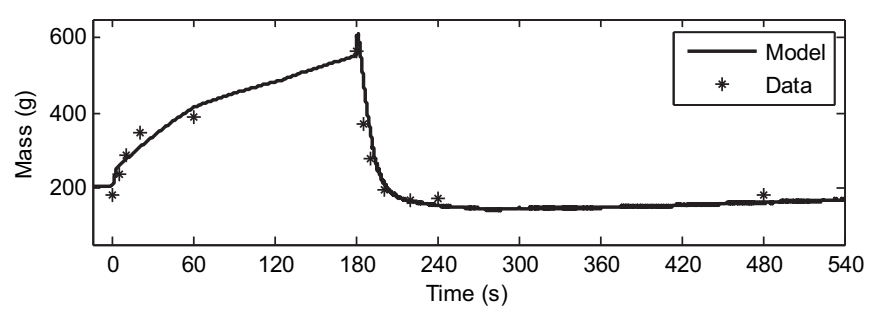

Fig. 18. Refrigerant mass migration in the accumulator. total evaporator tube length to add up to one. The accumulator holds $56 \%$ of the total refrigerant mass before start-up, and Fig. 18 presents the refrigerant mass migration inside the accumulator. During the off period, the pressure gradient drives the refrigerant migration from the evaporator to the accumulator component in the first $60 \mathrm{~s}$, and the migration continues as a result of the temperature gradient $[5,6,9,11]$. During the first $20 \mathrm{~s}$ of the system start-up, $35 \%$ of the total refrigerant mass leaves the accumulator.

\section{Conclusions and future work}

This paper presents dynamic modeling tools to capture the refrigerant mass migration during compressor shut-down and start-up operations in air conditioning and refrigeration systems. A dynamic R134a automotive air conditioning system model is introduced using the switched moving-boundary modeling approach proposed in [17]. The heat exchangers, along with the liquid tube, are developed with switched model representations to accommodate the refrigerant phase changes in cycling transients. The validation against experimental data from [9] shows that the system model is able to well predict the refrigerant mass migration among the system components during the shut-down period and the refrigerant redistribution after system start-up, with the mass prediction error between $4 \%$ and $8 \%$ for the specific example given here. Based on previous experience [17], it is anticipated that mass migration prediction errors would remain on the order of $10 \%$ or less for other similar scenarios. The results demonstrate the validity of the dynamic modeling approach presented. To the authors' knowledge, these represent a significant contribution since they are the inaugural presentation in the literature of a validated dynamic system model which captures the refrigerant mass migration in cycling operations.

The potential of the dynamic modeling tools can be investigated in the following two aspects, which are the focus of future work.

- Performance evaluation. With the developed modeling approach, it is possible to evaluate the refrigerant mass migration for different operating conditions (i.e., ambient temperature, different refrigerant fluids) and therefore predict the cycling performance of current air conditioning and refrigeration systems. Other objectives, such as different component designs or total refrigerant mass minimization, can be evaluated for transient scenarios.

- Control implementation. As discussed in Section 1, the refrigerant migration and redistribution have been identified as a major reason for the cycling losses. However, it is not always feasible to improve the system performance by completely avoiding the migration during the off period [15]. Therefore, it is important to investigate various means of operating the on and off cycles to both meet performance requirements and simultaneously manage refrigerant distribution. This balance can be achieved by adjusting the timing or duration of the on and off cycles. Another interesting option is the variation in the start-up and shut-down profiles to include ramping up and down the compressor speed. Regardless of the strategy, the modeling and simulation tools presented here offer a key enabler for considering various types of advanced control strategies to accomplish the aforementioned balance.

\section{Acknowledgements}

The authors are grateful for the financial support of the sponsoring companies of the Air-Conditioning and Refrigeration Center (ACRC) at the University of Illinois at Urbana-Champaign. 


\section{Nomenclature}

Symbols

A area $\left[\mathrm{m}^{2}\right]$

c specific heat $\left[\mathrm{kJ} \mathrm{kg}^{-1} \mathrm{~K}^{-1}\right]$

C flow coefficient [dimensionless]

E mass prediction error [dimensionless]

$f \quad$ forcing function

$h \quad$ refrigerant enthalpy $\left[\mathrm{kJ} \mathrm{kg}^{-1}\right]$

$K \quad$ gain in the pseudo-state equations; currently set to five $\left[\mathrm{s}^{-1}\right]$

$M \quad$ refrigerant mass [ $\mathrm{kg}]$

$\dot{m} \quad$ mass flow rate $\left[\mathrm{kg} \mathrm{s}^{-1}\right]$

NTU number of transfer units [dimensionless]

$P \quad$ refrigerant pressure $[\mathrm{kPa}]$

$\dot{Q} \quad$ heat transfer rate $[\mathrm{kW}]$

$T$ temperature $\left[{ }^{\circ} \mathrm{C}\right]$

$\vec{u} \quad$ input

$V \quad$ volume $\left[\mathrm{m}^{3}\right]$

$\vec{x} \quad$ state vector

Z coefficient matrix

\section{Greek letters}

$\alpha \quad$ average heat transfer coefficient $\left[\mathrm{kW} \mathrm{m}^{-2} \mathrm{~K}^{-1}\right]$

$\bar{\gamma} \quad$ mean void fraction [dimensionless]

$\rho \quad$ density $\left[\mathrm{kg} \mathrm{m}^{-3}\right]$

$\eta \quad$ efficiency [dimensionless]

$\zeta$ fraction of heat exchanger length covered by zone, also called normalized zone length [dimensionless]

\section{Subscripts}

$\begin{array}{ll}\text { ac } & \text { accumulator } \\ \text { amb } & \text { ambient } \\ \text { c } & \text { condenser }\end{array}$

c1, c2, c3 superheated, two-phase, sub-cooled zone in the

\section{condenser}

e evaporator

e1, e2 two-phase, superheated zone in the evaporator

etot complete evaporation from saturated liquid to saturated vapor

f saturated liquid

g saturated vapor

i inlet

$j \quad$ zone number; for the condenser, $j \in\{1,2,3\}$

(1, superheated; 2 , two-phase; 3 , sub-cooled); for the evaporator, $j \in\{1,2\}$ (1, two-phase; 2 , superheated)

lt liquid tube

o outlet

$\mathrm{v} \quad$ orifice tube

w heat exchanger structure (wall)

\section{References}

[1] E.B. Ratts, J.S. Brown, Experimental analysis of cycling in an automotive air conditioning system, Applied Thermal Engineering 20 (2000) 1039-1058.

[2] E. Björk, B. Palm, J. Nordenberg, A thermographic study of the on-off behavior of an all-refrigerator, Applied Thermal Engineering 30 (2010) 1974-1984.

[3] B. Li, R. Otten, V. Chandan, W.F. Mohs, J. Berge, A.G. Alleyne, Optimal on-off control of refrigerated transport systems, Control Engineering Practice 18 (12) (2010) 1406-1417.

[4] N. Tanaka, M. Ikeuchi, G. Yamanaka, Experimental study on the dynamic characteristics of a heat pump, ASHRAE Transactions 88 (pt 2) (1982) 323-331.

[5] W.J. Mulroy, D.A. Didion, Refrigerant migration in a split-unit air conditioner, ASHRAE Transactions 91 (pt 1A) (1985) 193-206.

[6] W.A. Miller, The laboratory evaluation of the heating mode part-load operation of an air-to-air heat pump, ASHRAE Transactions 91 (pt 2B) (1985) 524-536.

[7] M.I. Belth, T.E. Grzymala, D.R. Tree, Transient mass flow rate of a residential airto-air heat pump, International Journal of Refrigeration 11 (5) (1988) 298-304.
[8] E. Björk, B. Palm, Refrigerant mass charge distribution in a domestic refrigerator, part I: transient conditions, Applied Thermal Engineering 26 (2006) 829-837.

[9] S. Peuker, P.S. Hrnjak, Transient refrigerant migration and oil distribution of an R134a automotive A/C system, SAE International Journal of Passenger Cars - Mechanical Systems 2 (1) (2009) 714-724.

[10] P.J. Rubas, C.W. Bullard, Factors contributing to refrigerator cycling losses, International Journal of Refrigeration 18 (3) (1995) 168-176.

[11] W.E. Murphy, V.W. Goldsmidt, Transient response of air conditioner a qualitative interpretation through a sample case, ASHRAE Transactions 90 (pt 1B) (1984) 997-1008.

[12] M.H. Kim, C.W. Bullard, Dynamic characteristics of a R-410A split air-conditioning system, International Journal of Refrigeration 24 (7) (2001) 652-659.

[13] J.F. Judge, R. Radermacher, Transient and steady state performance of R-22 and R-407C, American Society of Mechanical Engineers, Advanced Energy Systems Division 34 (1995) 1-9.

[14] M.J.P. Janssen, J.A. de Wit, L.J.M. Kuijpers, Cycling losses in domestic appliances: an experimental and theoretical analysis, International Journal of Refrigeration 15 (3) (1992) 152-158.

[15] W.H. Coulter, C.W. Bullard, Experimental analysis of cycling losses in domestic refrigerator-freezers, ASHRAE Transactions 103 (1) (1997) 587-596.

[16] J. Wang, Y. Wu, Start-up and shut-down operation in a reciprocating compressor refrigeration system with capillary tubes, International Journal of Refrigeration 13 (3) (1990) 187-190.

[17] B. Li, A.G. Alleyne, A dynamic model of a vapor compression cycle with shutdown and start-up operations, International Journal of Refrigeration 33 (3) (2010) 538-552.

[18] S. Katipamula, A study of the transient behavior during start-up of residential heat pumps. Ph.D. Thesis Texas A\&M University (1989).

[19] W.E. Murphy, V.W. Goldsmidt, Cyclic characteristics of a typical residential air conditioner - modeling of start-up transients, ASHRAE Transactions 91 (pt 2A) (1985) 427-444.

[20] W.E. Murphy, V.W. Goldsmidt, Cyclic characteristics of a residential air conditioner - modeling of shutdown transients, ASHRAE Transactions 91 (pt 1A) (1986) 186-202.

[21] R.N.N. Koury, L. Machado, K.A.R. Ismail, Numerical simulation of a variable speed refrigeration system, International Journal of Refrigeration 24 (2) (2001) 192-200.

[22] M. Dhar, W. Soedel, Transient analysis of a vapor compression refrigeration system. In: Proceedings of the 15th International Congress of Refrigeration, Venice, Italy (1979)

[23] D. Ndiaye, M. Bernier, Transient modeling of refrigerant-to-air fin-and-tube heat exchangers, HVAC \& R research 16 (3) (2010) 355-381.

[24] S. Bendapudi, J.E. Braun, E.A. Groll, A comparison of moving-boundary and finite-volume formulations for transients in centrifugal chillers, International Journal of Refrigeration 31 (8) (2008) 1437-1452.

[25] C.J.L. Hermes, C. Melo, A first-principles simulation model for the start-up and cycling transients of household refrigerators, International Journal of Refrigeration 31 (8) (2008) 1341-1357.

[26] B. Ozyurt, A.N. Egrican, Experimental investigation of charge distribution in a vapor compression refrigeration cycle. In: Second IIR Workshop on Refrigerant Charge Reduction Stockholm Sweden (2010).

[27] T. Cheng, X.D. He, H. Asada, Nonlinear observer design and experimental verification for heat exchangers during the start-up process. Proceedings of the American Control Conference, Portland, OR, USA (2005) pp. 4814-4819.

[28] S. Peuker, P.S. Hrnjak, Experimental and Modeling Investigation of Two Evaporator Automotive Air Conditioning Systems. Air-Conditioning and Refrigerant Center TR-253 University of Illinois at Urbana-Champaign, 2006.

[29] S. Peuker, Experimental and analytical investigation of refrigerant and lubricant migration. Ph.D. Thesis University of Illinois at Urbana-Champaign (2010).

[30] T.L. McKinley, A.G. Alleyne, An advanced nonlinear switched heat exchanger model for vapor compression cycles using the moving-boundary method, International Journal of Refrigeration 31 (7) (2008) 1253-1264.

[31] B.P. Rasmussen, Dynamic modeling and advanced control of air conditioning and refrigeration systems. Ph.D. Thesis University of Illinois at UrbanaChampaign (2005).

[32] G. Mader, G.P.F. Fösel, L.F.S. Larsen, Comparison of the transient behavior of micro-channel and fin-and-tube evaporators. In: First IIR Workshop on Refrigerant Charge Reduction Cemagref Antony France (2009).

[33] B.D. Eldredge, B.P. Rasmussen, A.G. Alleyne, Moving-boundary heat exchanger models with variable outlet phase, Journal of Dynamic Systems, Measurement, and Control 130 (6) (2008) 0610031.

[34] F. Poggi, H. Macchi-Tejeda, D. Leducq, A. Bontemps, Refrigerant charge in refrigerating systems and strategies of charge reduction, International Journal of Refrigeration 31 (3) (2008) 353-370.

[35] G.L. Wedekind, B.L. Bhatt, B.T. Beck, A system mean void fraction model for predicting various transient phenomena associated with two-phase evaporating and condensing flows, International Journal of Multiphase Flow 4 (1) (1978) 97-114.

[36] S.M. Zivi, Estimation of steady-state steam void fraction by means of the principle of minimum entropy production, Journal of Heat Transfer 86 (1964) 247-252.

[37] E. Da Riva, D. Del Col., A. Cavallini, Modeling of performance and charge in minichannel heat exchangers. In: Second IIR Workshop on Refrigerant Charge Reduction Stockholm Sweden (2010)

[38] T.M. Harms, E.A. Groll, J.E. Braun, Accurate charge inventory modeling for unitary air conditioners, HVAC\&R Research 9 (1) (2003) 55-78. 
[39] W.M. Kays, A.L. London, Compact Heat Exchangers. McGraw-Hill, Inc., New York, NY, 1984.

[40] M.K. Dobson, J.C. Chato, Condensation in smooth horizontal tubes, Journal of Heat Transfer 120 (1) (1998) 193-213.

[41] J.P. Wattelet, J.C. Chato, B.R. Christoffersen, J.A. Gaibel, M. Ponchner, P.J. Kenney, R.L. Shimon, T.C. Villaneuva, N.L. Rhines, K.A. Sweeney, D.G. Allen,
T.T. Hershberger, Heat Transfer Flow Regimes of Refrigerants in A Horizontaltube Evaporator. Air-Conditioning and Refrigeration Center TR-55 University of Illinois at Urbana-Champaign, 1994.

[42] R.M. Manglik, A.E. Bergles, Heat transfer and pressure drop correlations for the rectangular offset strip fin compact heat exchanger, Experimental Thermal and Fluid Science 10 (2) (1995) 171-180. 